\title{
ТРАНСФЕР ТЕХНОЛОГИЙ КАК ЭКОНОМИЧЕСКИЙ ФЕНОМЕН
}

\section{В.Л. ГУРСКИЙ}

канд. экон. наук, доцент, заведующий кафедрой экономики

БИП-Института правоведения, г. Минск

\author{
В.А. КЛИМЕНКО \\ д-р соц. наук, профессор, \\ консультант Исполнительного комитета СНГ \\ В.С. ШУТ \\ аспирант кафедры «Экономика и право»
}

Белорусского национального технического университета, г. Минск

\section{Аннотация}

В статье проведен анализ теоретических основ трансферта технологий, рассматриваются проблемы влияния технологий на развитие начиональных и мировой экономик.

Ключевые слова: экономический рост, модернизация экономики, трансфер технологий, инновационная система.

Abstract

The article analyzes the theoretical bases of technology transfer are considered problems of the impact of technology on the development of national and world economies.

Keywords: economic growth, economy modernization, technology transfer, innovation system.

\section{ВВЕДЕНИЕ}

В последнее время особое значение приобретает формирование межгосударственного трансфера технологий, что является важным фактором экономического роста в странах-участниках ЕАЭС и ускоряет их переход к новейшим технологическим укладам. На сегодняшний день в каждой из стран-участников ЕАЭС созданы основы национальной инновационной системы, которая включает в себя ряд звеньев: институты государственного управления, субъекты инновационной инфраструктуры, инновационные фонды и венчурные организации, центры информационного и научного обеспечения, а также необходимую нормативную правовую базу для системной модернизации экономики и 
общества. Вместе с тем каждая из национальных инновационных систем стран-участников имеет свои особенности, которые характерны для определенного этапа развития научно-технического прогресса и проводимой инновационной политики, и наблюдается концептуальные и методологические расхождения в реализации политики технологических обменов между государствами.

\section{РЕЗУЛЬТАТЫ И ИХ ОБСУЖДЕНИЕ}

Уровень благосостояния населения любой страны мира, ее экономическое и политическое состояния сегодня во многом определяется конкурентоспособностью ее хозяйства. Последнее во многом определяется способностью экономических агентов генерировать и повсеместно использовать инновационные технологии. Нынешний этап развития мировой экономики характеризуется переходом экономически и технологически развитых государств от пятого к шестому технологическом укладу. Вместе с тем уже сегодня в рамках четвертого и пятого технологических укладов важнейшим условием достижения и сохранения высокой конкурентоспособности национальных экономик и коммерческих организаций является способность обеспечения непрерывности процесса создания и внедрения инноваций. Таким образом, технологическое обновление стало фактором, определяющим новое качество и устойчивость темпов экономического роста.

Успешность использования инноваций непосредственно зависит от эффективности использования трансфера технологий. В самом общем виде «трансфе́р технологий - основная форма продвижения инноваций. Это процесс передачи знаний, а также права на их использование, между физическими лицами или организациями с целью их последующего внедрения и/или коммерциализации» [1]. Трансфер технологий включает в себя: передачу либо отчуждение исключительного права на результаты интеллектуальной деятельности (как правило, объекты промышленной собственности); предоставление права на использование объектов интеллектуальной собственности в рамках лицензий; передачу технологической документации (как правило, в рамках лицензий на ноухау); передачу технологических сведений, сопутствующих приобретению или аренде (лизингу) оборудования и машин; информационный обмен в персональных контактах на семинарах, симпозиумах, выставках и т. п.; проведение различными фирмами и учеными совместных разработок и исследований; найм новых квалифицированных сотрудников, обладающих определенными знаниями; организацию совместного предприятия» [2].

Следует отметить, что в современном глобализирующемся мире трансфер технологий, осуществляется не изолировано, в рамках 
национальных экономик, а в условиях усиления международного разделения и кооперации труда. В результате чего национальные инновационные системы интегрированы в глобальные инновационные системы.

Несмотря на то, что в современной экономической науке и хозяйственной практике важность для инновационного развития национальных хозяйств их эффективного участия в международном трансфере технологий не оспаривается ни одним серьезным ученым и политиком, до настоящего времени отсутствует общепризнанный ответ на ключевой теоретический вопрос: почему происходят задержки в распространении технологий по всему миру? Ответить же на поставленный вопрос. По нашему мнению, невозможно без ответа на другой промежуточный вопрос: Лежат в основе явления задержки в распространении технологий по всему миру объективные или субъективные причины?

Эмпирически сегодня просматривается устойчивая тенденция к усиления политико-экономической поляризации мира, в основе которой лежит отрыв экономически развитых стран от развивающихся за счет быстрой и непрерывной технико-технологической модернизации своих экономик, а также широкого использования в хозяйственной жизни общественно-функциональных инноваций, причем значение последних в конкуренции хозяйственных систем постоянно усиливается. С.Ю. Солодовников справедливо подчеркивает, что «при достаточно глубоком рассмотрении любого экономического отношения в основе его всегда обнаруживается социальный обмен деятельностью. Прогресс человеческого общества неразрывно связан с оптимизацией этого обмена, критерием которого выступает снижение транзакционных издержек. Научно-технические достижения, разделение и кооперация труда, субординация и ординация между индивидами и многие другие социальные феномены и институты тем успешнее способствуют экономному получению человечеством необходимых вещества и энергии из природой, чем выше уровень социального прогресса в обществе. По мере усложнения общества разделенного труда названная зависимость усиливается. Это непосредственно предопределяется необходимостью предоставления большей степени экономической свободы хозяйственным субъектам, как основы для получения положительного синергетического эффекта от усложняющейся экономической системы общества» [3, с. 2]. На этой основе в странах золотого миллиарда произошло становление общества всеобщего благоденствия, основанного на постиндустриальной и/или сверхиндустриальной экономике.

Системный экономический анализ теоретических основ международного трансферта технологий затрудняется не только 
проблемами, связанными с феноменологической сложностью самого этого явления, но и тем, что до настоящего времени отсутствуют данные позволяющие количественно и качественно оценить эти трансферты. А в основе проверки истинности любого теоретического положения в экономической науке лежит именно практическое (эмпирическое) состояние исследуемого феномена. Следует также подчеркнуть, что в последнем случае возникает еще одна архи сложная проблема - способ статистического обобщения этого эмпирического материала. П.С. Лемещенко и И.А. Лаврухина справедливо напоминают по этому поводу, что «если обратиться к истории экономического анализа, то традиционными окажутся дискуссии не по самому фактическому материалу, а по способу его добычи, аргументации и тестировании» $[4$, с. 35$]$.

Проблемы влияния технологий на развитие национальных и мировой экономик в настоящее время достаточно изучены, благодаря таким зарубежным ученым как Д. Белл, С.Ю. Глазьев, П. Дракер, Н. Д. Кондратьев, Л. Туроу, Й. Шумпетер, К. Фримен, Ю. В. Яковец и многим другим. Их усилиями сегодня создана теория долгосрочного технико-экономического развития, описаны технологические предпосылки возникновения постиндустриального и сверх индустриального обществ, раскрыты инструменты и механизмы создания национальных и наднациональных инновационных систем, показаны пути и способы рационального использования инноваций экономическими агентами и т.д.

Вместе с тем до настоящего времени проблема международных технологических трансфертов исследована меньше всего. Не последнюю роль в этом сыграла идеологическая предвзятость либеральных экономистов, сводящих проблему международного перемещения технологий к только отсутствию в развивающихся странах рыночной свободы и адекватной этому институциональной среды. Очевидно, что подобного рода упрощение затрудняет объективное рассмотрение экономических явлений вообще и международного трансфера технологий в частности. С.Ю. Солодовников писал по этому поводу, что «существует гносеологическая необходимость рассматривать социально-экономические институты (рынок, общественно-функциональные инновации, инновационная деятельность и т.д.) как на социальные инструменты, позволяющие более или менее успешно облегчать жизнь людей - снижать транзакционные издержки. Такой подход должен позволить объективно (без вне исторической морализации) рассмотреть границы целесообразного применения инновационного инструментария в экономической системе общества во взаимоувязке с глобальными и национальными цивилизационными тенденциями, институциональной 
матрицей, материально-технологической средой...» [5, с. 5]. В свою очередь А.Л. Подгайский справедливо отмечает, что смысл прогресса «заключается не в нарастающем универсализме исторического процесса, а в умножении разнообразия социальных форм бытия, в позитивных результатах взаимодействия» [6, с. 8]. Названный автор также подчеркивает, что при этом необходимо учитывать, что «ни синергетика, ни цивилизационный подход не отрицают эвристического потенциала исследования общих тенденций, определяющих «лицо» человечества в целом. Но оба направления далеки от того, чтобы признавать за выводами таких исследований абсолютно значимый характер. Они настаивают лишь на универсальности общих принципов самоорганизации социальных систем. Отвергая представления об обществе как некотором однородном континууме, эти направления рассматривают в качестве истинных субъектов истории все многообразие социальных формирований между обществом и индивидом. Речь идет о том, что универсальные закономерности и черты социально-экономического прогресса в целом находят различное преломление в непреходящем разнообразии социальноэкономической действительности» [6, с. 8-9].

Белорусские экономисты внесли значительный, хотя до настоящего времени и не до конца осознанный зарубежными экономистами, вклад в осмысление проблемы международного трансфера технологий. Исследованиями в этой области успешно занимались Е.Л. Давыденко, А.В. Данильченко, Г.В. Турбан, Л.Н. Нехорошева и многие другие.

К. Перес удалось путем диалектического снятия противоречий в теоретических взглядах сторонников длинных волн Н. Кондратьева решить проблему происхождения задержек в распространении технологий по всему миру. Напомним, что Н. Кондратьев писал, что «большие циклы важнейших элементов экономической жизни имеют международный характер, причем в отношении европейских капиталистических стран периоды этих циклов близко совпадают» [7, с. 370]. Далее названный автор подчеркивал, что «на основании приведенных данных можно утверждать, что последнее положение имеет силу и для США. Однако это не мешает думать, что в динамике развития капитализма этой страны, и в частности в период колебания ее динамики, имеются и свои особенности» [7, с. 370].

К. Перес пишет, что каждая новая технологическая парадигма «распространяется волнообразно: от сектора к сектору через индустриальную структуру, и географически в каждой стране и во всем мире» $[8$, с. 96]. При этом любая технологическая революция начинает проявляться «с группы основных отраслей промышленности, обычно задействуя некоторые источники энергии или другие универсальные ресурсы, новую инфраструктуру и несколько главных продуктов и процессов» $[8$, с. 96]. После чего революционные технологические 
изменения видоизменяют и смешные с основными отрасли. В результате чего, как справедливо подчеркивает У. Перес: «Формируется интерактивная система с очень высоким уровнем синергии и эффективной обратной связью. Это способствует улучшению понимания элементов парадигмы и восприятию их как хорошо проверенных все более широким кругом отраслей и занятий. Таким образом усиливаются внешние эффекты (экстерналии) и снижаются издержки приспособления парадигмы ко все новым видам деятельности, и, поскольку институциональные условия становятся благоприятными, все составляющие экономики в рамках своих инновационных траекторий постепенно настолько осваивают парадигму, что она начинает восприниматься как "естественный путь" для выгодной, эффективной и результативной работы» [8, с. 96]. Следует обратить внимание на очень важное и справедливое замечание цитируемого автора о том, что институциональные условия становятся благоприятными после приспособления новой технологической парадигмы ко все новым видам деятельности, а не наоборот. Вопреки широко развитому мнению среди отечественных либерально настроенных экономистов технологическая модернизация не происходит после проведения радикальных институциональных преобразований, а наоборот соответствующие новейшему технологическому укладу новые институты зарождаются и зреют под воздействием объективных технико-экономических процессов, естественным образом эволюционно подстраиваясь под эти процессы.

К. Перес категорически заявляет, «...что "чудеса" синергии, интенсивного роста и процветания, которым дает ход каждая технологическая революция, переносятся на все более дальние области, от наиболее развитых областей к наименее развитым. Такой процесс можно рассматривать как проявление всеохватывающей мировой конвергенции с заключительным этапом в виде распространения данной парадигмы, хотя к тому времени обнаруживаются расхождения ведущих стран под влиянием следующей технологической революции и начала становления ее элементов. Это вскоре должно свести на нет некоторые преимущества, достигнутые на периферии» [8, с. 96]. Таким образом, становится видна методологическая, теоретическая и практическая несостоятельность концепции «догоняющего развития», поскольку при ее последовательном применении страна становится на путь консервации своего места технологической и экономической периферии, а значит уровень благосостояния ее населения всегда будет существенно ниже чем в странах технологически развитых. Последнее обстоятельство будет способствовать усилению трудовой миграции из стран технологической периферии в страны лидеры. Последнее обстоятельство также будет ухудшать конкурентные возможности страны, ставшей на путь «догоняющего развития» за счет «утечки мозгов», миграции из нее квалифицированных 
рабочих и талантливой молодежи. Таким образом, использование варианта «догоняющего развития» может применяться развивающимися странами, странами с переходной экономикой, только как относительно не продолжительный этап адаптации к новым экономико-технологическим тенденциям международных экономических отношений.

В пользу последнего умозаключения выступает и тот факт, что текущая технологическая волна «...в каждой своей фазе, вероятно, будет иметь во многом схожий характер» [8, с. 100], но «поскольку главной особенностью нынешнего века информации является создание глобальной экономики, то производственные и торговые сети с самого начала инсталляционного периода стали распространяться и в ведущих и в периферийных странах, - пишет К. Перес, - Такая особенность, вероятно отличает эту волну от всех предыдущих с точки зрения ее распространения от ведущих к остальным странам» [8, с. 100]. Названная особенность новой технологической парадигмы, то, что ее распространение предполагает длительное сосуществование перехлестывающихся кондратьевских волн и отсутствие автоматизма в распространении новых технологий от центра к периферии, свидетельствуют о решающем значении государственной политики для привлечения зарубежных технологий и использования их в целях тотальной модернизации народного хозяйства. «Переход к постиндустриальной экономике не означает исчезновение аграрного и индустриального укладов, а сохранение последних, но уже не как доминирующих, а как периферийных, - подчеркивает вслед за Д. Беллом, С.Ю. Солодовников. - При этом постиндустриальный уклад становится доминирующим. В итоге усложняется сложность социальноэкономических процессов» [9, с. 3].

Таким образом, анализ теоретических основ трансферта технологий показывает, что без научно-обоснованной и последовательной государственной политики по участию в международных технологических трансфертах Республика Беларусь не сможет обеспечить высокий уровень благосостояния страны за счет модернизации народного хозяйства на основе новейших технологий. При этом задачей государства в сфере международных технологических трансфертов является создание условий для использования любого своего преимущества для создания платформы для инноваций и выгодного использования имеющихся возможностей.

\section{ВЫВОДЫ}

Установлено, что новая технологическая парадигма распространяется неравномерно от сектора к сектору через индустриальную структуру, и географически в каждой стране и во всем мире не автоматически. Доказано, что стратегия «догоняющего развития» в случае ее 
абсолютизации ведет к сохранению роли страны как мировой технологической и экономической периферии, а значит и к консервации уровня благосостояния ее населения, которое в результате всегда будет существенно ниже, чем в технологически развитых странах. Выяснено, что задачей государства в сфере международных технологических трансфертов является создание условий для использования любого своего преимущества для создания платформы для инноваций и выгодного использования имеющихся возможностей.

\section{ЛИТЕРАТУРА}

1. Электронный pecypc. Трансфер технологий. https://ru.wiki pedia.org/wiki. Режим доступа 23.05.2016 г.

2. Электронный peсурс. Трансфер технологий. https://ru.wiki pedia.org/wiki. Режим доступа 23.05.2016 г.

3. Солодовников С.Ю. Социальный капитал как экономический ресурс //Вестник Полоцкого государственного университета. Серия D. экономические и юридические науки. - 2015. - №5.

4. П.С. Лемещенко, И.А. Лаврухина Экономическая наука Беларуси: путь к самоидентификации // Вестник Ивановского государственного университета // Серия «Экономика», Вып. 1(19), 2013.

5. Солодовников С.Ю. Новая парадигма инновационного развития белорусской экономики и подходы к ее формированию // Вестник Полоцкого государственного университета. Серия D: Экономические и юридические науки. - 2011. - № 14.

6. Подгайский, А.Л. Взаимодействие доминирующих и переферийных укладов как составляющая социально-экономической динамики / А.Л. Подгайсктй // Гуманітарна-эканамічны веснік. - 2008. № 3 (42).

7. Кондратьев Н.Д. Большие циклы экономической конъюктуры / Н.Д. Кондратьев, Ю.В. Яковец, Л.И. Абалкин // Большие циклы конъюктуры и теория предвидения. Избранные труды. М.: Экономика, 2002.

8. Перес К. Технологические революции и финансовый капитал. Динамика пузырей и периодов процветания. - М. : Изд-во «Дело» АНХ, 2011. $-232 \mathrm{c}$.

9. Солодовников С.Ю. Тенденции и перспективы развития занятости и создания социально-научного сообщества в условиях модернизации транзитивной экономики: на примере Республики Беларусь // Вестник Полоцкого государственного университета. Серия D: Экономические и юридические науки. - 2015. - № 6.

Статья поступила в редакцию 24 ноября 2016 года. 